\title{
Protection of metal artifacts with the formation of metal-oxalates complexes by Beauveria bassiana
}

\section{Edith Joseph ${ }^{1,2}$ *, Sylvie Cario ${ }^{2}$,Anaële Simon ${ }^{2}$, Marie Wörle $^{1}$, Rocco Mazzeo ${ }^{3}$, Pilar Junier ${ }^{2}$ and Daniel Job ${ }^{2}$}

1 Laboratory of Conservation Research, Sammlungszentrum, Swiss National Museum, Affoltern am Albis, Switzerland

${ }^{2}$ Laboratory of Microbiology, Institute of Biology, University of Neuchâtel, Neuchâtel, Switzerland

${ }^{3}$ Microchemistry and Microscopy Art Diagnostic Laboratory, University of Bologna, Ravenna, Italy

Edited by:

Weiwen Zhang, Tianjin University, China

\section{Reviewed by:}

Liang Shi, Wright State University, USA

Shawn Chen, Ohio University, USA

${ }^{*}$ Correspondence:

Edith Joseph, Laboratory of

Conservation Research,

Sammlungszentrum, Swiss National

Museum, Lindenmoosstrasse 1, 8910

Affoltern am Albis, Switzerland.

e-mail: edith.joseph@snm.admin.ch
Several fungi present high tolerance to toxic metals and some are able to transform metals into metal-oxalate complexes. In this study, the ability of Beauveria bassiana to produce copper oxalates was evaluated. Growth performance was tested on various coppercontaining media. B. bassiana proved highly resistant to copper, tolerating concentrations of up to $20 \mathrm{~g} \mathrm{~L}^{-1}$, and precipitating copper oxalates on all media tested. Chromatographic analyses showed that this species produced oxalic acid as sole metal chelator. The production of metal-oxalates can be used in the restoration and conservation of archeological and modern metal artifacts. The production of copper oxalates was confirmed directly using metallic pieces (both archeological and modern). The conversion of corrosion products into copper oxalates was demonstrated as well. In order to assess whether the capability of $B$. bassiana to produce metal-oxalates could be applied to other metals, iron and silver were tested as well. Iron appears to be directly sequestered in the wall of the fungal hyphae forming oxalates. However, the formation of a homogeneous layer on the object is not yet optimal. On silver, a co-precipitation of copper and silver oxalates occurred. As this greenish patina would not be acceptable on silver objects, silver reduction was explored as a tarnishing remediation. First experiments showed the transformation of silver nitrate into nanoparticles of elemental silver by an unknown extracellular mechanism. The production of copper oxalates is immediately applicable for the conservation of copper-based artifacts. For iron and silver this is not yet the case. However, the vast ability of $B$. bassiana to transform toxic metals using different immobilization mechanisms seems to offer considerable possibilities for industrial applications, such as the bioremediation of contaminated soils or the green synthesis of chemicals.

Keywords: Beauveria bassiana, metal immobilization, oxalates, bioremediation, conservation science

\section{INTRODUCTION}

Fungi play an essential role in the bioweathering of rocks and minerals, and especially in the transformation of metals, which are present in large quantities in mineral components. This transformation regulates metal bioavailability through either solubilization or immobilization (Gadd, 2007). The capability to accumulate and precipitate metals has biotechnological applications and can be exploited for the bioremediation of metal-polluted soils and waste treatment (Gadd, 2010).

Leaching of metals by fungi is the result of different mechanisms promoted by proton efflux or metabolites with chelating properties. Metal immobilization can also occur through others processes of reductive metal precipitation such as the synthesis of metallic nanoparticles (Gadd, 2007). Among the metabolites with chelating properties, some of the most common are carboxylic acids and in particular oxalic acid. In previous studies, different species of fungi were studied for their production of oxalic acid and transformation of metal-containing minerals (Sayer and Gadd, 1997; Gharieb et al., 2004). This includes a few papers published on the precipitation of toxic metals as metal-oxalates, as for example copper oxalates by entomopathogenic fungi such as Beauveria species (Fomina et al., 2005) and iron oxalates by ectomycorrhizal fungi (Landeweert et al., 2001).

On the other hand, there is a growing interest for the synthesis of inorganic materials by biological means because these are more environmental friendly processes. Novel applications of this are the use of microorganisms for corrosion control or protection of stone monuments, which were recently illustrated in literature (Cappitelli et al., 2006; Zuo, 2007). In the field of conservation, this could represent an innovative treatment for archeological and artistic metal artifacts. This will be in contrast to the treatments currently employed such as the application of organic protective coatings, which simply create a barrier against aggressive environments in a non-selective way.

As part of the Biological patinA for arcHaeological and Artistic Metal ArtefactS (BAHAMAS) project, a novel approach based on inorganic treatments addressing specific corrosion features is envisaged for copper, iron, and silver. These substrates are widely represented in cultural heritage artwork and face several problems of active corrosion. The research activities foreseen aim at creating 
protective fungal patinas by the conversion of existing corrosion products into more stable and less soluble compounds while maintaining the surface's physical appearance. The color of the oxalate layer created will be different according to the treated metal substrate and is expected to be green, red-brown, and white on the respective copper/bronze, iron, and silver substrates. As part of this project, the aim of the present study was to evaluate the ability of Beauveria bassiana to tolerate and transform copper, iron, and silver compounds into stable compounds, such as metal-oxalate complexes. The performance of $B$. bassiana was compared with four other phylogenetically related soil fungal species in order to establish whether $B$. bassiana is exceptionally promising for this biotechnological application.

\section{MATERIALS AND METHODS STRAINS}

Beauveria bassiana was isolated from copper-contaminated vineyard soil (Bevaix Abbey, Neuchâtel, Switzerland). The Bevaix abbey vineyard soil (Neuchâtel, Switzerland) was treated for more than a century with copper-based pesticide agents and is highly contaminated with $\mathrm{Cu}$ (total concentration in soil reaches $350 \mathrm{ppm}$ ). Trichophyton mentagrophytes (MUCL 9823), Trichophyton rubrum (MUCL 11954), Arthroderma quadrifidum (MUCL 9822), and Geomyces pannorum (MUCL 151) were provided from the culture collection BCCM/MUCL of the University of Louvain (Belgium). The five strains are deposited in the culture collection of the Microbiology Laboratory (University of Neuchatel).

\section{MEDIA AND CULTURE CONDITIONS}

Agar malt extract medium (MA; $15 \mathrm{~g} \mathrm{~L}^{-1}$ agar and $12 \mathrm{~g} \mathrm{~L}^{-1}$ malt in distilled water) was autoclaved at $121^{\circ} \mathrm{C}, 25 \mathrm{~min} \mathrm{~L}^{-1}$. Different metal compounds were added to the medium for the specific experiments (Table 1). Brochantite $\mathrm{Cu}_{4}(\mathrm{OH})_{6}\left(\mathrm{SO}_{4}\right)_{4}$ and atacamite $\mathrm{Cu}_{2} \mathrm{Cl}(\mathrm{OH})_{3}$ were synthesized according to the literature (Sharkey and Lewin, 1971; Tanaka et al., 1991). Cuprite $\mathrm{Cu}_{2} \mathrm{O}$, hematite $\mathrm{Fe}_{2} \mathrm{O}_{3}$, and silver nitrate $\mathrm{AgNO}_{3}$ were purchased from Fluka (purum). Magnetite $\mathrm{Fe}_{3} \mathrm{O}_{4}$ and iron (III) oxide $\mathrm{FeOOH}$ were supplied by Aldrich (99.99\%) and acanthite $\mathrm{Ag}_{2} \mathrm{~S}$ by Riedelde Haën (pure). The different metal compounds were sterilized with an UV-rays exposure of $30 \mathrm{~min}$ and added to the media after autoclaving. When biocides were used, these were added after autoclaving to the melted malt agar media at a temperature lower than $60^{\circ} \mathrm{C}$. Cultures were incubated (unless otherwise stated) at room temperature in the dark.

\section{GROWTH PERFORMANCE TEST}

Pre-cultures onto MA petri dishes incubated at room temperature were used as inocula. Square fungal plugs of $5 \mathrm{~mm}$ side were taken out with a sterilized cork borer and placed onto new Petri dishes containing the different modified solid media summarized in Table 1. The media (two or three replicates for each composition) were incubated at room temperature for 18 days ( 8 days for iron) and the mycelia growth diameters measured. The growth rates were determined measuring the radial growth diameters of the mycelium each 3-4 days in two directions at $90^{\circ}$ angles (Trinci, 1971; Griffin et al., 1974; Prosser, 1994). MA medium was used as a control.

\section{ORGANIC ACID ANALYSIS}

Beauveria bassiana was grown at room temperature for 21 days on two different malt agar media that contained $15 \mathrm{~g} \mathrm{~L}^{-1}$ agar and 8 or $12 \mathrm{~g} \mathrm{~L}^{-1}$ malt in distilled water (three replicates for each composition). Cultures were filtrated on $0.2 \mu \mathrm{m}$ Whatman paper and cell filtrates were lyophilized and suspended in $100 \mu \mathrm{L}$ deionized water. The organic acids excretion was analyzed using high performance liquid chromatography (HPLC) with a UV-VIS DAD detector. A calibration was established using 11 different organic acids as standards. An Agilent HPLC 1100 series controller was used with an ion-exchange column ( $\mathrm{H}^{+}$form, Benson, Reno, $\mathrm{NV}$, USA) and sulfuric acid $(20 \mathrm{mM})$ as eluent. Forty-five microliters portions of triplicate samples were eluted for $20 \mathrm{~min}$ at $7 \mathrm{~mL} \mathrm{~min}^{-1}$. UVVIS absorbance spectra of the acid function $\mathrm{C}=\mathrm{O}$ were collected between 210 and $400 \mathrm{~nm}$.

\section{SAMPLES}

Two copper washers (W33 and W34), one Roman bronze $(\mathrm{Cu} / \mathrm{Sn})$ alloy coin (C1), and one copper coin from France (Louis XIII Double Tournois, C2) were used to evaluate the copper oxalate formation in a liquid medium. Two copper roof sheets (R1 and $\mathrm{R} 2,0.1 \mathrm{~cm} \times 1.5 \mathrm{~cm} \times 2 \mathrm{~cm}$ ) were used for evaluate the copper oxalates formation in a solid medium. Two iron washers (W37 and W38) and two iron nails (N58 and N59) were used for evaluate the iron oxalates formation in a liquid medium. The experiments with solid media were performed on four window hinges (Fe1-Fe4) and four iron screws (Fe6-Fe9). The silver oxalates formation was evaluated on a one Swiss Franc coin ( $\mathrm{Ag} 83.5 \% / \mathrm{Cu} 16.5 \%$ alloy) C3 from 1966.

\section{FORMATION OF METAL-OXALATES ON SAMPLES}

The different objects were not sterilized and placed in $85-\mathrm{mm}$ diameter Petri dishes. For copper, a malt medium containing $12 \mathrm{~g} \mathrm{~L}^{-1}$ malt was used for the cultures in liquid medium on samples W33, W34, C1, and C2 (immersion $<2 \mathrm{~mm}$ ). For assays in solid medium cultures with copper, MA, and MABRO media (Table 1) were put onto the copper roof sheets R1 and R2 and their shape adapted to the size of the samples. The thickness of the solid media was $2 \mathrm{~mm}$. Finally $B$. bassiana was inoculated under a laminar flow hood using aliquots of spores suspended in water. Conidies were collected from cultures of B. bassiana onto MA petri dishes and suspended in deionized water in order to obtain enough conidies per square millimeter of the samples surface (at

Table 1 | Composition of the different media used for the growth rates measurements.

\begin{tabular}{ll}
\hline Medium & Composition \\
\hline MA & $12 \mathrm{~g} \cdot \mathrm{L}^{-1} \mathrm{malt}+15 \mathrm{~g} \cdot \mathrm{L}^{-1}$ agar \\
MABRO & $\mathrm{MA}+5 \mathrm{~g} \cdot \mathrm{L}^{-1}$ brochantite \\
MACUP & $M A+5 \mathrm{~g} \cdot \mathrm{L}^{-1}$ cuprite \\
MAACAN & $M A+5 \mathrm{~g} \cdot \mathrm{L}^{-1}$ acanthite \\
MAHE & $M A+5 \mathrm{~g} \cdot \mathrm{L}^{-1}$ hematite \\
MAMA & $M A+5 \mathrm{~g} \cdot \mathrm{L}^{-1}$ magnetite \\
MAIOH & $M A+5 \mathrm{~g} \cdot \mathrm{L}^{-1}$ iron (III) oxide
\end{tabular}


least 200 conidies for each Petri dish). The copper oxalates formation was evaluated during 3 weeks through optical microscopy observations and FTIR spectroscopy analysis every week. An identical protocol was followed for iron. Solid media MA, MAHE, MAMA, and MAIOH were used on samples Fe1-Fe4 and Fe6-Fe9. Liquid medium (malt $12 \mathrm{~g} \mathrm{~L}^{-1}$ ) was used on iron nails N58 and N59 and on iron washers W37 and W38. The precipitation of silver oxalates was evaluated on the sample C3 using a MA medium. The experimental protocol was the same as the one developed for copper.

\section{FORMATION OF SILVER NANOPARTICLES}

The experimental protocol was adapted from the literature (Vigneshwaran et al., 2007; Birla et al., 2009; Ingle et al., 2009). Conidia were collected from cultures of $B$. bassiana onto MA petri dishes and suspended in deionized water in order to obtain a final concentration of $8 \times 10^{5}$ spores $\mathrm{mL}^{-1}$. Two milliliters aliquots of $B$. bassiana spores were used to inoculate $250 \mathrm{ml}$ Schott flasks each containing $100 \mathrm{~mL}$ of a malt medium $\left(12 \mathrm{~g} \mathrm{~L}^{-1}\right)$ and the flasks were placed under agitation $(125 \mathrm{rpm})$ for $150 \mathrm{~h}$ in dark at room temperature. The culture was filtered on an 11- $\mu \mathrm{m}$ Whatman filter (previously sterilized under UV for $40 \mathrm{~min}$ ) in order to separate mycelium and cell filtrate. The mycelium (in $24.5 \mathrm{~mL}$ deionized water) and $24.5 \mathrm{~mL}$ cell filtrate were inoculated each in $250 \mathrm{~mL}$ Schott flasks. Silver nitrate was added to obtain a final concentration of $6 \mathrm{mM} \mathrm{Ag}^{+}$ions. The flasks were then incubated at room temperature under agitation $(125 \mathrm{rpm})$ for $72 \mathrm{~h}$. Controls were prepared in the same way but adding $24.5 \mathrm{~mL}$ deionized water instead.

\section{CHARACTERIZATION OF TRANSFORMATION PRODUCTS Optical microscopy}

Bright field observations were performed using an Leica DMR optical microscope equipped with fixed oculars of $10 \times$ and objectives with different magnifications $(5,10,40$, and $100 \times)$. Photomicrographs were recorded with a Nikon DXM1200 digital camera directly connected to the microscope and controlled through the ACT-1 software.

Scanning electron microscopy and energy dispersive spectroscopy A Tescan Mira LMU environmental scanning electron microscope, equipped with an energy dispersive X-ray analyzer was used to observe the crystals formed by B. bassiana. The samples were lyophilized, covered with carbon and gold layers, and finally observed in the secondary electron mode at an acceleration voltage of $15 \mathrm{kV}$ and a working distance of 5-25 mm.

\section{FTIR microscopy}

A Biorad Excalibur spectrometer coupled with a Varian UMA500 FTIR microscope fitted with an MCT detector cooled by liquid nitrogen was used for FTIR measurements. The measurements were made either in reflection mode or in transmission mode using a micro diamond compression cell. All spectra were acquired in the range $4000-650 \mathrm{~cm}^{-1}$, at a spectral resolution of $4 \mathrm{~cm}^{-1}$. A total of 64 scans were recorded and the resulting interferogram averaged. Data collection and post-run processing were carried out using Varian resolutions Pro $^{\mathrm{TM}}$ software.

\section{X-ray diffraction}

A calibration was established using mixtures of dihydrated copper oxalate $\left(\mathrm{CuC}_{2} \mathrm{O}_{4} \cdot 2 \mathrm{H}_{2} \mathrm{O}\right)$ and quartz with exact proportion. The cultures of B. bassiana in MABRO, MATA, and MACUP media were dried at $60^{\circ} \mathrm{C}$ and then ground to a homogenous powder with particle size $<40 \mu \mathrm{m}$. For each $\mathrm{Cu}$ (II) concentration, one sample of $800 \mathrm{mg}$ has been pressed (20 bars) in a powder holder covered with a blotting paper and analyzed by XRD, using a SCINTAG 2000 Diffractometer, Thermo, Ecublens, Switzerland. Fixed analysis conditions were as follows: wave length: $1.5406 \AA \mathrm{Cu} \mathrm{K} \alpha$; generator power: $45 \mathrm{kV}$ and $40 \mathrm{~mA}$; emitting slits: 2, $4 \mathrm{~mm}$; receiving slits: $0.5,0.3 \mathrm{~mm}$; continuous $2 \theta$ scan from $1^{\circ}$ to $65^{\circ}$; step size: $0.02^{\circ}$; scan rate $1.00 / \mathrm{min}$; acquisition step size (chopper increment; $\left.0.03^{\circ} 2 \theta\right)$.

\section{UV-VIS spectroscopy}

Two-milliliter aliquots of cell filtrate were centrifuged at $10,000 \mathrm{~g}$ for $10 \mathrm{~min}$ and rinsed three times with deionized water. Mycelium was centrifuged at $10,000 \mathrm{~g}$ for $10 \mathrm{~min}$, rinsed three times with deionized water and homogenized with a ultrasonic bath. Sodium chloride was added in order to precipitate the remaining silver (I) ions, which would interfere with the measurements. A UV-VIS Thermo Genesis $10 \mathrm{~s}$ spectrometer was used and absorbance spectra were recorded between 300 and $800 \mathrm{~nm}$ with $1 \mathrm{~nm}$ resolution.

\section{Statistical analysis}

All statistical analyses were performed using R software. For experimental results on solid media with iron compounds, the significance $(p<0.05)$ of differences among growth rates was evaluated using one-way ANOVA for parametric data and a complementary Tukey's post hoc test.

\section{RESULTS AND DISCUSSION EFFECT OF DIFFERENT COPPER COMPOUNDS ON GROWTH AND PRECIPITATION OF COPPER OXALATES IN $B$. bassiana}

In order to test the ability of $B$. bassiana to tolerate and immobilize copper through the precipitation of copper oxalates, this strain was exposed to $\mathrm{Cu}$ (II) present in different chemical forms (Cu oxide, hydroxysulfate, and hydroxychloride). Growth performance was compared with a control medium containing only a carbon source but no $\mathrm{Cu}$ (II) (MA medium). In MA, B. bassiana had the highest growth rate $\left(3.9 \mathrm{~mm} \mathrm{day}^{-1}\right)$ compared to copperenriched solid media, which significantly altered growth rates. On medium supplemented with increasing concentrations of cuprite ( $\mathrm{Cu}$ oxide, MACUP medium) growth rates decreased to $0.35 \pm 0.06 \mathrm{~mm} \mathrm{day}^{-1}$ at 10 and to $0.35 \pm 0.03 \mathrm{~mm} \mathrm{day}^{-1}$ at $20 \mathrm{~g} \mathrm{~L}^{-1}$ and reduced to $0.20 \pm 0.03 \mathrm{mmday}^{-1}$ at $50 \mathrm{~g} \mathrm{~L}^{-1}$ (Figure 1A). Likewise, growth rates severely decreased for media containing brochantite ( $\mathrm{Cu}$ hydroxysulfate, MABRO medium; Figure 1A). Despite the elevated toxicity of chlorides for fungi, this strain developed on atacamite ( $\mathrm{Cu}$ hydroxychloride, MATA medium) with concentrations of $\mathrm{Cu}$ chloride up to $20 \mathrm{~g} \mathrm{~L}^{-1}$ and had a radial growth of $0.60 \pm 0.10 \mathrm{~mm} \mathrm{day}^{-1}$. However, B. bassiana growth was fully inhibited at $50 \mathrm{~g} \mathrm{~L}^{-1}$ of atacamite (Figure 1A). The lowest $B$. bassiana growth was on MACUP media and could be related to the higher solubility of cuprite in water respect to brochantite and atacamite (Cramer et al., 2002). 

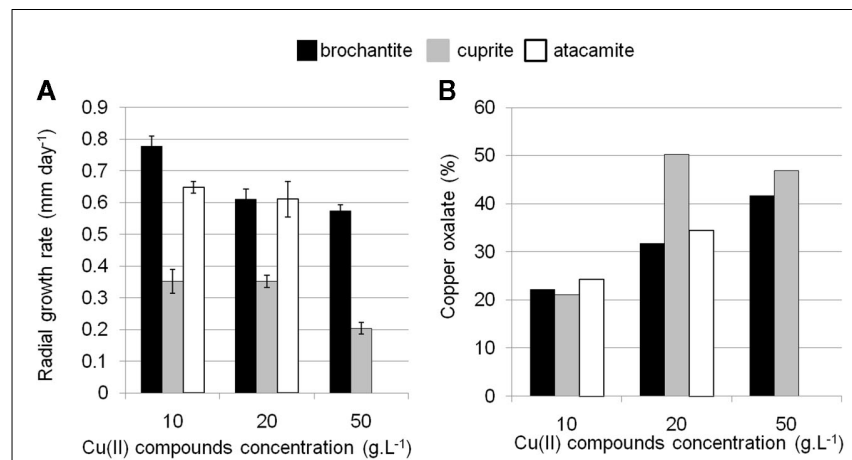

FIGURE 1 | Ability of $\boldsymbol{B}$. bassiana to tolerate and form copper oxalates on different soil media containing cuprite (MACUP), brochantite (MABRO), and atacamite (MATA). (A) Radial growth rates on solid media amended with $\mathrm{Cu}(\mathrm{II})$ concentrations ranging from 10 to $50 \mathrm{~g} \mathrm{~L}^{-1}$. The bars reflect mean values of three replicates. Error bars indicate SEs of the means. (B) Copper oxalates semi-quantitative estimation calculated from the XRD measurements and expressed in percentage of the dry weight of treated mycelium.

After 18 days of incubation, green concentric ring patterns were observed on the surface of the MACUP and MABRO Petri dishes, suggesting the solubilization of copper and its transformation into copper oxalates within Liesegang rings. Such patterns are formed when reaction, diffusion, and precipitation processes interact together (Henisch, 1988). After 3 months of incubation, the amount of copper oxalates precipitated by B. bassiana was estimated by XRD analysis (Figure 1B). In general, the amount of copper oxalates increased with the amount of copper available in the medium. With $10 \mathrm{~g} \mathrm{~L}^{-1}$ of copper, the amount of copper represented $22.5 \%$ of the total weight and rose to $38.9 \%$ with $20 \mathrm{~g} \mathrm{~L}^{-1}$ and $44.3 \%$ with $50 \mathrm{~g} \mathrm{~L}^{-1}$. The results illustrated that in presence of more copper, B. bassiana precipitated a larger quantity of copper oxalates. This feature together with the stimulation of oxalic acid production was already reported for other fungal species and in particular for brown rot basidiomycetes (Clausen and Green, 2003).

Beauveria bassiana was isolated from vineyard soil that was treated for centuries with copper-based pesticide agents. It certainly developed a resistance toward high concentrations of copper ions, as suggested by the results presented below. It is worth mentioning that $B$. bassiana is part of the entomopathogenic fungi group, whose copper resistance is already reported in the literature (Baath, 1991). In order to test whether the ability of $B$. bassiana to tolerate copper is exceptional, four other soil fungi were tested for their ability to tolerate and immobilize copper through the precipitation of copper oxalates. In control medium (MA), $B$. bassiana grew at a slightly faster rate $\left(3.94 \pm 0.35 \mathrm{~mm} \mathrm{day}^{-1}\right)$ than A. quadrifidum and G. Pannorum, which had rates of $3.8 \pm 0.26$ and $2.47 \pm 0.06 \mathrm{~mm} \mathrm{day}^{-1}$ respectively (Figure 2A). The two Trichophyton strains (T. mentagrophytes and T. rubrum) grew with the lowest rates $\left(2.29 \pm 0.06\right.$ and $1.51 \pm 0.04 \mathrm{~mm} \mathrm{day}^{-1}$, respectively). However, the $\mathrm{Cu}$ protection mechanisms of strains others than B. bassiana seemed limited, as they were not able to grow on MABRO or MACUP media (Figures $2 B, C$ ). On MABRO, only

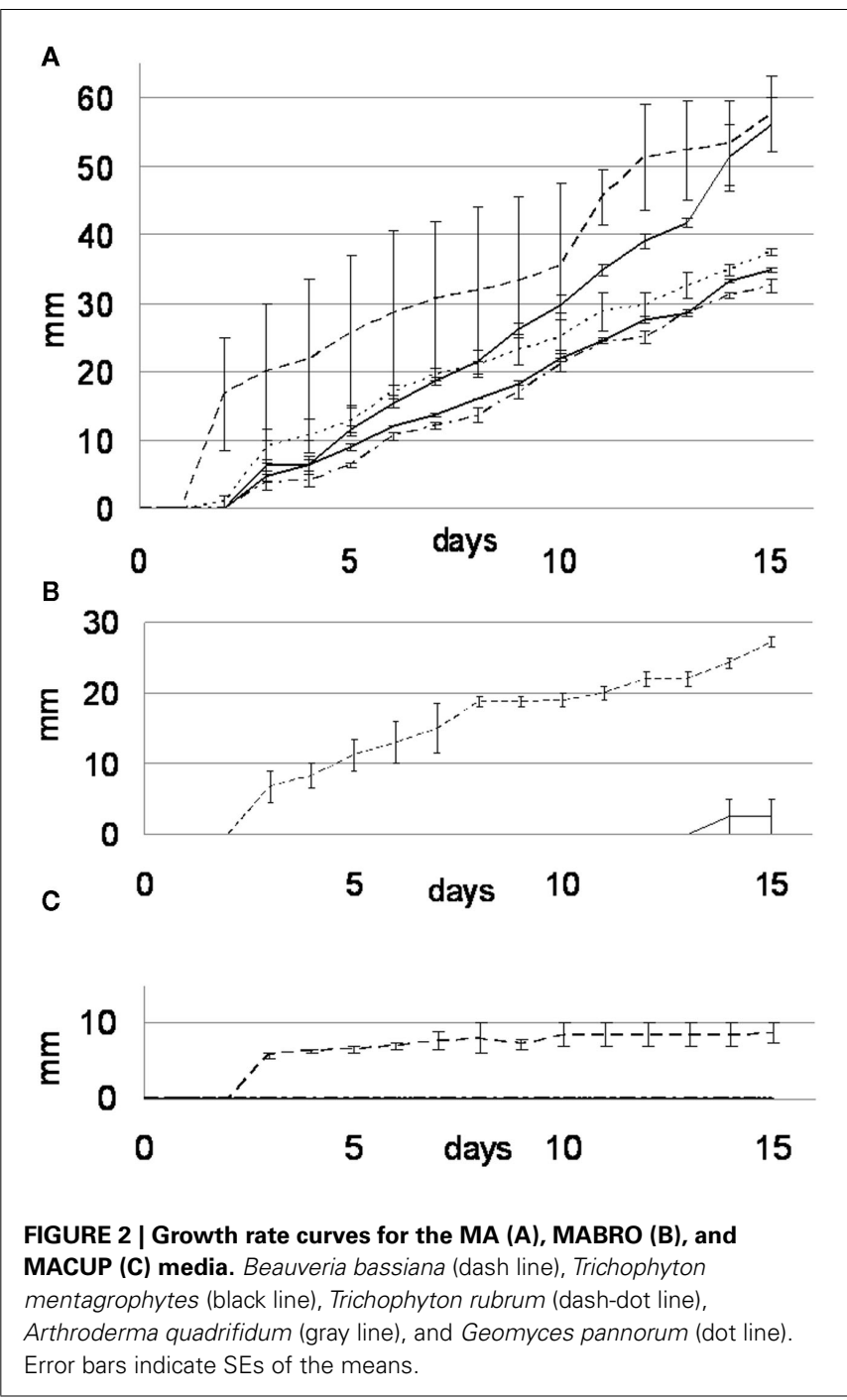

A. quadrifidum $\left(0.26 \pm 0.26 \mathrm{~mm} \mathrm{day}^{-1}\right)$ developed marginally (Figure 2B). On MACUP none of the four other strains was able to grow (Figure 2C).

Regarding the immobilization mechanism used by B. bassiana, HPLC analyses combined with UV-VIS spectroscopy revealed that this strain excreted considerable amounts of oxalic acid and none of the other organic acids evaluated (Figure 3). The concentration of oxalic acid produced varied at different concentrations of malt. In $8 \mathrm{~g} \mathrm{~L}^{-1}$ of malt, $23.3 \mathrm{~kg} \mathrm{~m}^{-3} \mathrm{day}^{-1}$ of oxalic acid was produced. This value increased to $31.6 \mathrm{~kg} \mathrm{~m}^{-3}$ day $^{-1}$ when the concentration of malt was increased to $12 \mathrm{~g} \mathrm{~L}^{-1}$. Based on these values, the theoretical total production of oxalic acid after 21 days of incubation, would be of $489 \mathrm{~kg} \mathrm{~m}^{-3}$ on solid medium containing $8 \mathrm{~g} \mathrm{~L}^{-1}$ of malt and $663 \mathrm{~kg} \mathrm{~m}^{-3}$ with $12 \mathrm{~g} \mathrm{~L}^{-1}$ of malt. For comparison, in Aspergillus niger, which is the most important fungi studied for production of oxalic acid, production is up to 10 times lower considering the values reported for wild $\left(3.7 \mathrm{~kg} \mathrm{~m}^{-3} \mathrm{day}^{-1}\right)$ or mutant $\left(9.7 \mathrm{~kg} \mathrm{~m}^{-3} \mathrm{day}^{-1}\right)$ strains. In addition, $A$. niger excreted also citric and gluconic acid (Cameselle et al., 1998; Rymowicz and Lenart, 2003). 
In addition, the characterization of copper oxalates formed by $B$. bassiana was further performed by means of ESEM observations, XRD, and FTIR measurements (Joseph et al., 2011). These data completed the work here presented. ESEM observations allowed characterizing the crystals as rounded foil-like concretions, which were identified as moolooite $\left(\mathrm{CuC}_{2} \mathrm{O}_{4} \cdot \mathrm{nH}_{2} \mathrm{O}\right.$ with $n<1$ ), a natural hydrated copper oxalate by XRD and FTIR measurements on the three media MACUP, MABRO, and MATA.

\section{APPLICATION OF OXALATE BIOPATINAS ON COPPER/BRONZE \\ SAMPLES}

The precipitation of copper oxalates presented here has a potential application in the field of art conservation science. In fact, on outdoor exposed bronzes, copper oxalates are identified but not associated with the phenomenon of cyclical corrosion (Graedel et al., 1987). Instead they form green protective patinas on the bronze surface, which are highly insoluble and chemically stable even in acidic atmospheres (Marabelli and Mazzeo, 1993). Thus, considering the production of copper oxalates demonstrated in B. bassiana prompted the evaluation of the formation of a homogenous layer of copper oxalates on corroded artifacts.

After 3 weeks of incubation of $B$. bassiana in liquid medium in the presence of several copper-containing objects, the formation of copper oxalates was observed on the different samples (Figure 4). The green copper oxalates were distributed around the sample either on the edge of the sample (W33 and W34) or in the surrounding medium (samples $\mathrm{C} 1$ and C2; Figures 4A,B). Such application procedure is therefore unsuitable for the purpose of creating a homogeneous and adherent layer of copper oxalates on the samples. We designed another application procedure where the fungi can be directly inoculated on a solid medium that has been previously poured onto the samples. Copper roof sheets were used for this optimized application procedure. Optical microscopy observations on the R1 and R2 coupons have shown that either within MA or MABRO media, copper oxalates crystals formed and were already visible after 7 days of incubation (Figures 4C,D). Moreover, a higher amount of copper oxalates

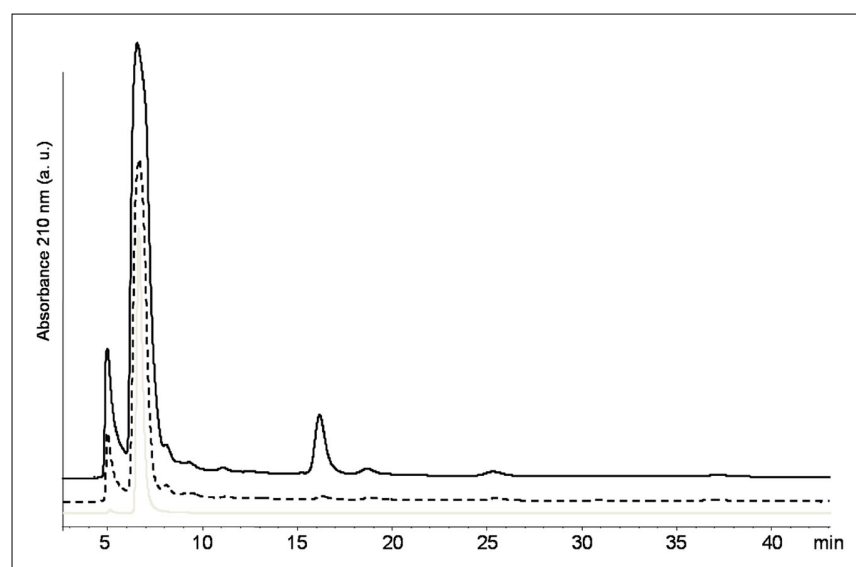

FIGURE 3 | High performance liquid chromatography separation spectra for $B$. bassiana cultures on MA medium with $8 \mathrm{~g} \mathrm{~L}^{-1}$ (black line) and $12 \mathrm{~g} \mathrm{~L}^{-1}$ (dash line) of malt together with the HPLC reference spectra of oxalic acid (gray line). appeared to be formed in MA medium (Figure 4C) respect to MABRO (Figure 4D), and suggested that the addition of copper to the medium did not increase the copper oxalates precipitation. The surface of the treated samples was characterized by FTIR measurements (Figure 5). The results showed that the original patina composed of brochantite is gradually transformed into copper oxalates and that the conversion is all but complete on the surface areas where B. bassiana had grown.
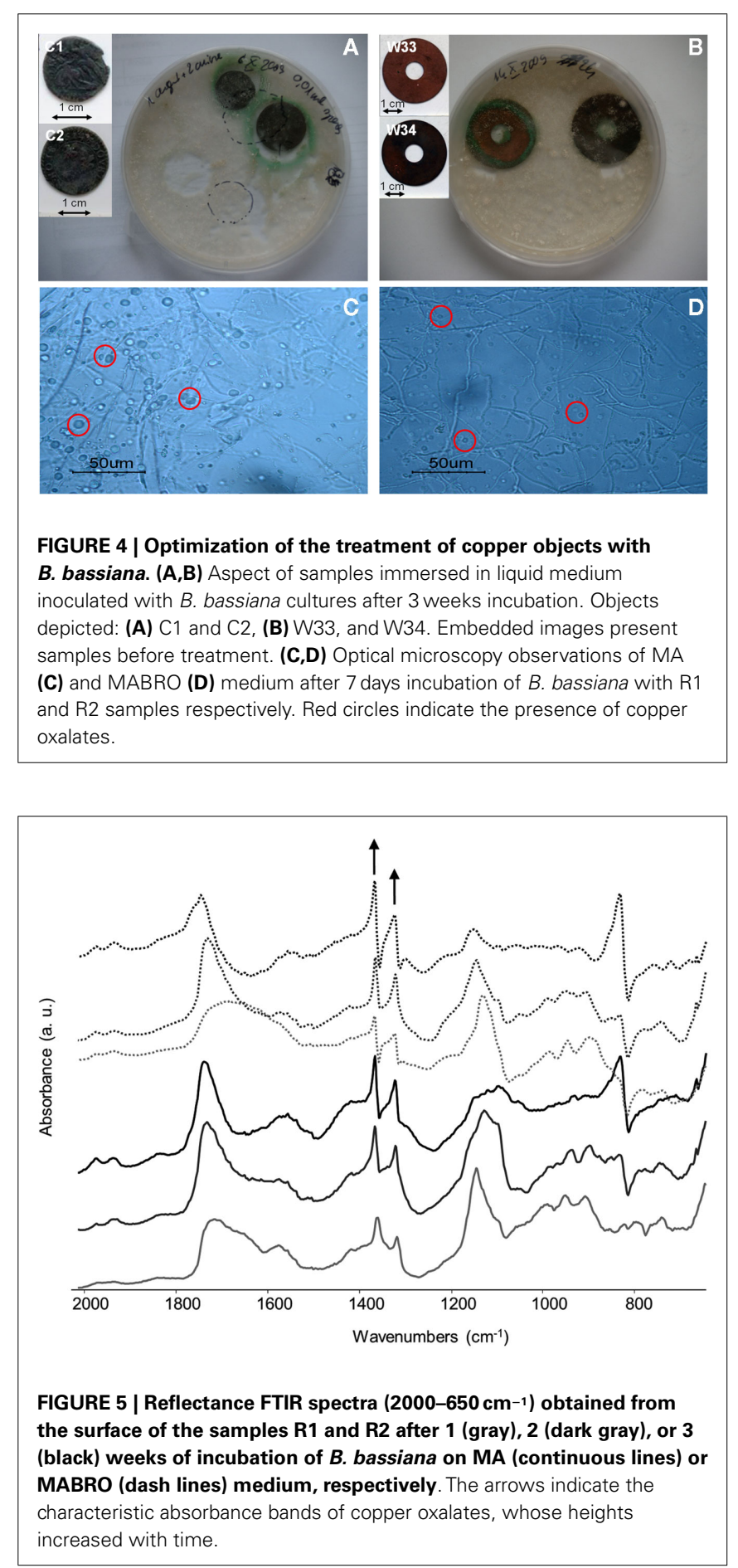


\section{APPLICATION ON IRON AND SILVER SAMPLES}

Considering the encouraging results obtained for coppercontaining objects, the ability of $B$. bassiana to precipitate iron oxalates, form silver oxalates, or to reduce silver compounds to elemental silver was evaluated as well. To our knowledge this is the first time that such an attempt is conducted.

\section{Iron oxalates formation}

The ability of $B$. bassiana to transform and immobilize iron was tested on different iron compounds. Growth rates were significantly different $(F=52.18, \mathrm{df}=4, p=0.00001)$ for all tested media. Among the different iron-containing media, B. bassiana demonstrated to have a much higher growth on $\mathrm{MAIOH}$ than on the other two media tested (Figure 6). These results were in agreement with the fact that iron is essential to fungi and not as toxic as copper. Even after 45 days of incubation, no crystal formation was observed within the media.

Since our primarily interest is to obtain iron oxalate layers over art objects, a first attempt was made with iron samples on different solid media. After 2 months of incubation with MAHE, some hyphae adopted a red coloration under optical microscopy observations (data not shown). However contamination did not allow an accurate evaluation for all other media and further experiments will be therefore be foreseen with the use of antibiotics in order to obtain a selective medium for B. bassiana. Follow up experiments performed on iron samples (N58, N59, W37, and W38) in liquid media gave very promising results: after a few weeks, hyphae around the samples presented a red coloration. Optical microscopy showed that hyphae close to the objects accumulated a dark red aggregate and seemed completely incrusted with red crystals (Figure 7A). The crystals were characterized by SEM observations and FTIR measurements. SEM observations allowed observing the encrustation of crystals around hyphae (Figure 7B). Further, FTIR analyses showed the presence of characteristics absorbance bands at $1366\left(\nu_{\mathrm{s}} \mathrm{C}-\mathrm{O}\right), 1320\left(\nu_{\mathrm{s}} \mathrm{C}-\mathrm{O}\right)$, and $822(\delta \mathrm{C}-\mathrm{O}) \mathrm{cm}^{-1}$ (Figure 7C), which can be attributed to iron oxalates (D'Antonio et al., 2009). Based on these results, further test should be performed to lessen the amount of water used for example a spray for the aspersion of the culture over the pieces.

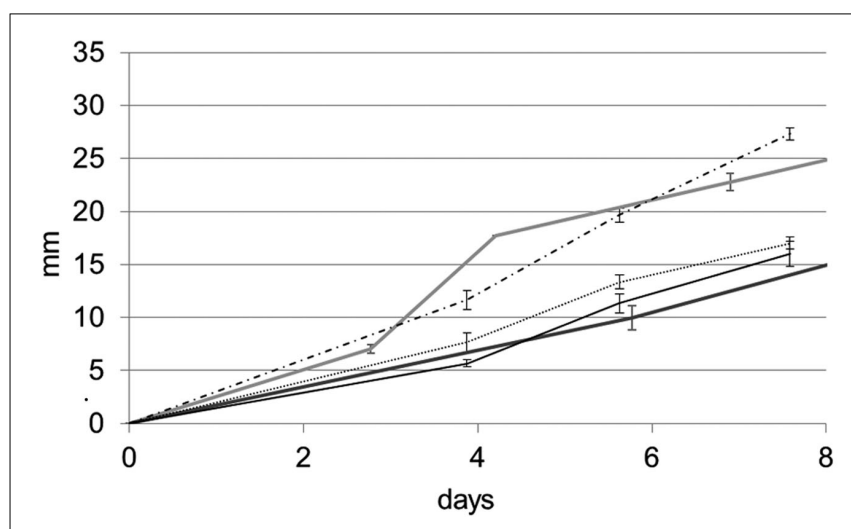

FIGURE 6 | Growth rate curves for the B. bassiana cultures on MA (gray line) MABRO (dark gray line), MAHE (black line), MAMA (dot line), and MAIOH (dash-dot line) media. Error bars indicate SEs of the means.

\section{Silver oxalates and nanoparticles precipitation}

For the growth performance of B. bassiana on silver compounds the highest growth rate was obtained in MAACAN medium $\left(3.4 \mathrm{~mm} \mathrm{day}^{-1}\right)$. Optical observations showed the presence of few rectangular and bipyramidal crystals (3-4 $\mu \mathrm{m}$ length; Figure 8A). The same crystal morphology was reported in the literature for silver oxalate aggregates (Boldyrev, 2002; Pourmortazavi et al., 2008), but due to the small amount of crystals observed, any attempt to characterize these crystals with SEM-EDS and FTIR microscopy was not possible. However, the mechanism for silver immobilization in B. bassiana seemed similar to that for copper, as the same extracellular precipitation was observed. It is worth saying that most silver artifacts are based on a copper-silver alloy and a green patina will therefore be formed by the precipitation of copper oxalates as for sample C3 (Figure 8B). In these cases, the esthetic value of the objects will thus be altered, as a color change of the object's surface is not acceptable as far as conservation ethics are concerned. Hence, the formation of an eventual homogeneous and compact layer of silver oxalates appeared problematic for the conservation of silver artifacts.

Therefore a different conservation strategy against the tarnishing of silver artifacts based on the synthesis of silver nanoparticles was tested. As reported in the literature, some fungi are able to transform silver nitrate into silver metal nanoparticles (Rai et al., 2009). This may represent an innovative conservation method where tarnished areas could be reverted back to metal silver. The ability of $B$. bassiana to synthesize $\mathrm{Ag}^{0}$ nanoparticles was tested either in liquid medium or within a cell filtrate (Figure 8C). After 3 days of incubation, UV-VIS spectroscopy analysis showed a characteristic absorbance band at $420 \mathrm{~nm}$, which was absent in the controls and can be attributed to the presence of $\mathrm{Ag}^{0}$ nanoparticles due a Plasmon resonance phenomenon. Comparing the mycelium and cell filtrate spectra, the peak height is much higher in this latter

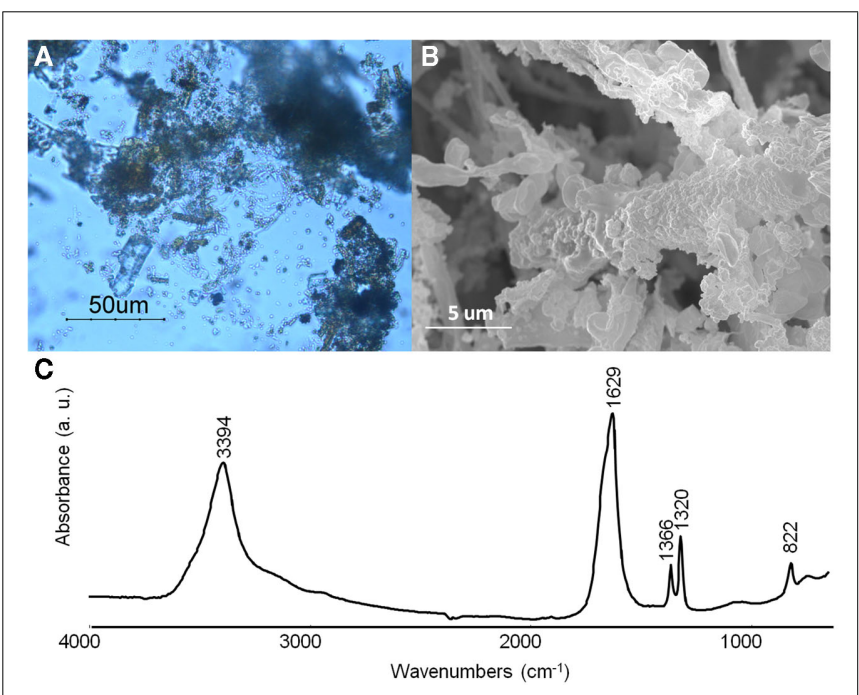

FIGURE 7 | Beauveria bassiana cultures on MA medium with iron sample W38. (A) Optical microscopy observations. (B) Secondary electron image. (C) Transmittance FTIR spectrum $\left(4000-650 \mathrm{~cm}^{-1}\right)$ obtained from hyphae incrusted in red crystals. 


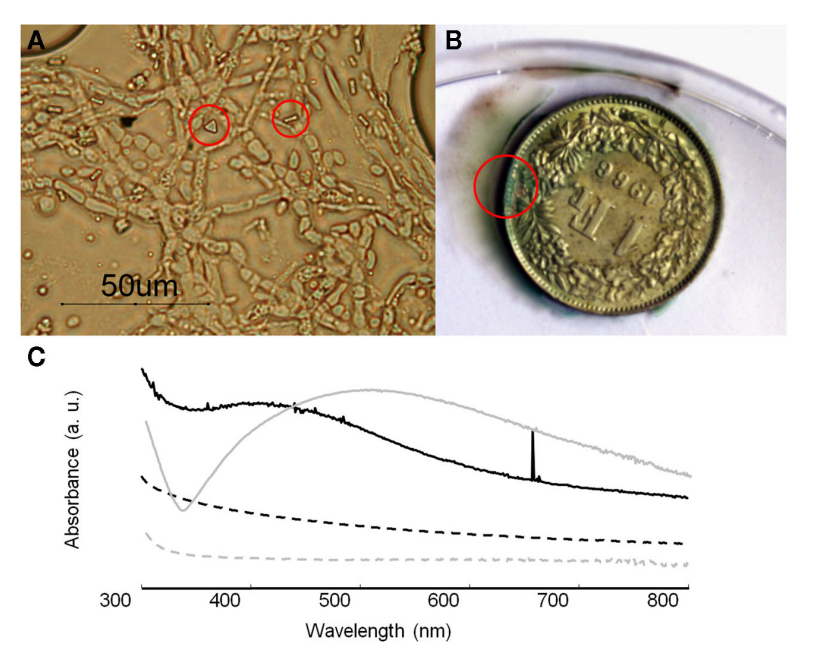

FIGURE 8 | Growth of $\boldsymbol{B}$. bassiana on silver compounds. (A) Optical microscopy observations of $B$. bassiana cultures on MAACAN medium with rectangular and bipyramidal crystals indicated by red circles. (B) Sample C3 (copper-silver alloy) with copper oxalates formed around the area indicated by a red circle. (C) UV-visible absorbance spectra of mycelium (black line) and cell filtrate (dash line) containing silver nanoparticles. As control the reference spectra for mycelium (gray line) and cell filtrate (gray dash line) were included.

confirming the synthesis of metal nanoparticles by a still unknown extracellular enzyme (Ingle et al., 2009). This simple and ecofriendly biosynthesis of silver nanoparticles by B. bassiana seemed very promising in particular in the field of nanotechnology, where such materials are studied for their antimicrobial properties.

\section{REFERENCES}

Baath, E. (1991). Tolerance of copper by entomogenous fungi and the use of copper-amended media for isolation of entomogenous fungi from soil. Mycol. Res. 95, 1140-1142.

Birla, S. S., Tiwari, V. V., Gade, A. K., Ingle, A. P., Yadav, A. P., and Rai, M. K. (2009). Fabrication of silver nanoparticles by Phoma glomerata and its combined effect against Escherichia coli, Pseudomonas aeruginosa and Staphylococcus aureus. Lett. Appl. Microbiol. 48, 173-179.

Boldyrev, V. V. (2002). Thermal decomposition of silver oxalate. Thermochim. Acta 388, 63-90.

Cameselle, C., Bohlmann, J. T., Núñez, M. J., and Lema, J. M. (1998). Oxalic acid production by Aspergillus niger. Bioprocess Biosyst. Eng. 19, 247-252.

Cappitelli, F., Zanardini, E., Ranalli, G., Mello, E., Daffonchio, D., and Sorlini, C. (2006). Improved methodology for bioremoval of black crusts

\section{CONCLUSION AND PERSPECTIVES}

In this study, the ability of $B$. bassiana to grow in presence of $\mathrm{Cu}$ ions and to form copper oxalate crystals on different media was highlighted. Moreover, the possibilities offered by the use of $B$. bassiana as an innovative conservation approach were demonstrated. In fact, the results of the HPLC analysis showed the specific production of oxalic acid. This feature will allow us to create oxalate patinas without the formation of other carboxylates, as it could be the case for other fungal strains producing a combination of carboxylic acids. In addition, the precipitation of iron oxalates and silver nanoparticles was reported for the first time. The different crystal aggregates were characterized by either SEM, XRD measurements, or UV-VIS spectroscopy. Further FTIR analysis permitted to observe the gradual conversion of copper sulfates into oxalates and to identify iron oxalates. B. bassiana is a cosmopolite fungi, which has been widely applied as insecticide following eco-friendly processes. Therefore, safety concerns are minimal and this will allow the development of an in situ application kit for conservators-restorers.

\section{ACKNOWLEDGMENTS}

This research has been partially carried out with the support of the European Union, within the VII Framework Program (Contract: BAHAMAS, PIEF-GA-2009-252759, 2010-2012). Authors acknowledge Mr. T. Adatte and Dr. P. Vonlanthen (Institute of geology and paleontology, University of Lausanne, Switzerland) for providing X-ray diffraction and SEM-EDS facilities, respectively and for their assistance during experiments. Authors are also grateful to the analytical service of the Faculty of Sciences, University of Neuchâtel and in particular Dr. A. Vallat for assistance during experiments.

acid over excretion in transformations of toxic metal minerals by Beauveria caledonica. Appl. Environ. Microbiol. 71, 371-381.

Gadd, G. M. (2007). Geomycology: biogeochemical transformations of rocks, minerals, metals and radionuclides by fungi, bioweathering and bioremediation. Mycol. Res. 111, 3-49.

Gadd, G. M. (2010). Metals, minerals and microbes: geomicrobiology and bioremediation. Microbiology 156, 609-643.

Gharieb, M. I., Ali, M. I., and El-Shoura, A. A. (2004). Transformation of copper oxychloride fungicide into copper oxalate by tolerant fungi and the effect of nitrogen source on tolerance. Biodegradation 15, 49.

Graedel, T. E., Nassau, K., and Franey, J. P. (1987). Copper patinas formed in the atmosphere - I. Introduction. Corros. Sci. 27, 639.

Griffin, D. H., Timberlake, W. E., and Cheney, J. C. (1974). Regulation of macromolecular synthesis, colony development, and specific growth rate of Achlya bisexualis during balanced growth. J. Gen. Microbiol. 80, 381-388.

Henisch, H. (1988). Crystals in Gels and Liesegang Rings: In vitro Veritas. Cambridge: Cambridge University Press.

Ingle, A., Rai, M., Gade, A., and Bawaskar, M. (2009). Fusarium solani: a novel biological agent for the extracellular synthesis of silver nanoparticles. J. Nanopart. Res. 11, 2079-2085

Joseph, E., Simon, A., Prati, S., Wörle, M., Job, D., and Mazzeo, R. (2011). Development of an analytical procedure for evaluation of the protective behaviour of innovative fungal patinas on archaeological and artistic metal artefacts. Anal. Bioanal. Chem. 399, 2899-2907.

Landeweert, R., Hoffland, E., Finlay, R. D., Kuyper, T. W., and Van Breemen, N. (2001). Linking plants to rocks: ectomycorrhizal fungi mobilize nutrients from minerals. Trends Ecol. Evol. (Amst.) 16, 248-254. 
Marabelli, M., and Mazzeo, R. (1993). La corrosione dei bronzi esposti all'aperto: problemi di caratterizzazione. La Metallurgia Italiana 85, 247-254.

Pourmortazavi, S. M., Hajimirsadeghi, S. S., Kohsari, I., Fareghi Alamdari, R., and Rahimi-Nasrabadi, M. (2008). Determination of the optimal conditions for synthesis of silver oxalate nanorods. Chem. Eng. Technol. 31, 1532-1535.

Prosser, J. I. (1994). "Kinetics of filamentous growth and branching," in Growing Fungus, eds N. A. R. Gow and G. M. Gadd (London: Chapman \& Hall), 301-318.

Rai, M., Yadav, A., and Gade, A. (2009). Silver nanoparticles as a new generation of antimicrobials. Biotechnol. Adv. 27, 76-83.
Rymowicz, W., and Lenart, D. (2003). Oxalic acid production from lipids by a mutant of Aspergillus niger at different pH. Biotechnol. Lett. 25, 955-958.

Sayer, J. A., and Gadd, G. M. (1997). Solubilization and transformation of insoluble inorganic metal compounds to insoluble metal oxalates by Aspergillus niger. Mycol. Res. 101, 653-661.

Sharkey, J. B., and Lewin, S. Z. (1971). Conditions governing the formation of atacamite and paratacamite. Am. Mineral. 56, 181-194.

Tanaka, H., Kawano, M., and Koga, N. (1991). Thermogravimetry of basic copper(II) sulphates obtained by titrating $\mathrm{NaOH}$ solution with CuSO4 solution. Thermochim. Acta 182, 281.

Trinci, A. P. J. (1971). Influence of the width of the peripheral growth zone on the radial growth rate of fungal colonies on solid media. J. Gen. Microbiol. 67, 325-344.

Vigneshwaran, N., Kathe, A. A., Varadarajan, P. V., Nachane, R. P., and Balasubramanya, R. H. (2007). Silver-protein (core-shell) nanoparticle production using spent mushroom substrate. Langmuir 23, 7113-7117.

Zuo, R. (2007). Biofilms: strategies for metal corrosion inhibition employing microorganisms. Appl. Microbiol. Biotechnol. 76, 1245-1253.

Conflict of Interest Statement: The authors declare that the research was conducted in the absence of any commercial or financial relationships that could be construed as a potential conflict of interest.
Received: 04 November 2011; accepted: 20 December 2011; published online: 09 January 2012.

Citation: Joseph E, Cario S, Simon $A$, Wörle $M$, Mazzeo $R$, Junier $P$ and Job D (2012) Protection of metal artifacts with the formation of metal-oxalates complexes by Beauveria bassiana. Front. Microbio. 2:270. doi: 10.3389/fmicb.2011.00270

This article was submitted to Frontiers in Microbiotechnology, Ecotoxicology and Bioremediation, a specialty of Frontiers in Microbiology.

Copyright (C) 2012 Joseph, Cario, Simon, Wörle, Mazzeo, Junier and Job. This is an open-access article distributed under the terms of the Creative Commons Attribution Non Commercial License, which permits non-commercial use, distribution, and reproduction in other forums, provided the original authors and source are credited. 